\title{
CD45 to Lymphocyte Ratio Measurement
}

National Cancer Institute

\section{Source}

National Cancer Institute. CD45 to Lymphocyte Ratio Measurement. NCI Thesaurus.

Code C122106.

The determination of the ratio of CD45 expressing cells to total lymphocytes present in a sample. The measurement by be expressed as a ratio or percentage. 